\title{
Characteristics of attenders and their attendances at an urban accident and emergency department
} over a one year period

\author{
A W Murphy, C Leonard, P K Plunkett, H Brazier, R Conroy, F Lynam, G Bury
}

\section{Department of \\ General Practice, \\ National University of Ireland, Galway, Ireland \\ A W Murphy \\ C Leonard \\ Department of Accident and Emergency Medicine, St James's Hospital, Dublin \\ P K Plunkett}

Mercer Library, Royal College of Surgeons in Ireland Medical School, Dublin

H Brazier

Department of

Epidemiology, Royal College of Surgeons in Ireland Medical

School, Dublin

R Conroy

Medical Information Systems, St James's

Hospital, Dublin

F Lynam

Department of

General Practice,

University College

Dublin

G Bury

Correspondence to:

Dr Murphy.

Accepted 29 May 1999

\begin{abstract}
Objectives-To describe (1) the characteristics of attenders to an urban accident and emergency (A\&E) department over a one year period according to the frequency of their attendance and (2) the features of their attendances according to the frequency which the patient attended the department during the study period. Methods-A dataset containing information on all new attendances to an urban A\&E department in 1995 was formed. For each attendance the following information was recorded: day of the week, hour of attendance, referral source, triage category, and disposal. A second dataset, consisting of the individuals ("attenders") who made the A\&E visits ("attendances") during 1995 was also produced. For each attender the following information was recorded: age, sex, postal code of residence, socioeconomic status, marital status, and number of attendances during 1995. A methodology reviewing the trends of frequency of attendance was utilised, as opposed to the use of an arbitrary cut off point.
\end{abstract}

Results-34908 patients made 46735 visits in 1995. Increasing frequency of attendance was significantly associated with increasing age (Kruskal-Wallis $<0.001$ ), being male ( $\chi^{2}$ for linear trend 14.06, $\mathrm{p}<0.001$ ), having a local postal address $\left(\chi^{2} 279.79, \mathbf{p}<0.0001\right)$, general medical services eligibility $\left(\chi^{2} 781.67\right.$, $\mathbf{p}<0.0001$ ), and inversely associated with being married $\left(\chi^{2} 33.91, p<0.0001\right)$. Increasing frequency of attendance was significantly associated with attendance between the hours of 1700 and $0900\left(\chi^{2}\right.$ 295.62 , $p<0.001$ ), being triaged as a nonemergency $\left(\chi^{2} 1254.33, p<0.0001\right)$, and self referral $\left(\chi^{2} 141.4, p<0.0001\right)$.

Conclusions-A small group of $A \& E$ attenders accounts for a disproportionately large percentage of the total number of departmental attendances. The characteristics of frequent $A \& E$ attenders suggest that they may represent a vulnerable group of patients. A follow up study of the utilisation of all primary care services by such patients is suggested.

(F Accid Emerg Med 1999;16:425-427)

Keywords: attendances; A\&E departments; primary care
Frequent attenders to accident and emergency (A\&E) departments are considered problematical for various reasons, including their effect on departmental workload and waiting times, presentation of multiple chronic health problems not readily treatable on an emergency basis, and their origin from perceived socially stigmatised groups. ${ }^{1}$ Most studies that focus specifically on this group are from the United States or Scandinavia and usually arbitrarily define frequent attenders as those with more than three visits in a 12 month period. ${ }^{2-5} \mathrm{We}$ therefore thought it appropriate to conduct a study of $A \& E$ attenders at a hospital in the British Isles and to use a methodology reviewing the trends of frequency of attendance, rather than an arbitrary cut off point.

The objectives of this paper are to describe: (1) the characteristics of attenders to an urban $A \& E$ department over a one year period according to the frequency of their attendance and (2) the features of their attendances according to the frequency which the patient attended the department during the study period.

\section{Methods}

St James's is a major Dublin teaching hospital with 490 acute beds serving a catchment population of 219300 . The medical staff complement in the $\mathrm{A} \& \mathrm{E}$ department is one consultant, three registrars, and 10 senior house officers. Nursing staff include three sisters and 31 nurses. Demographic and a limited amount of clinical information concerning all ambulatory and admitted patients is kept on a mainframe computer by the hospital medical information systems department.

From this system, a dataset containing information on all new attendances to the hospital A\&E department from 1 January 1995 to 31 December 1995 inclusive was formed. Excluded from this dataset were those patients who had been requested to return to the department for reasons such as clinical review or dressing application. For each attendance the following information was recorded: day of the week, hour of attendance, referral source, triage category, and disposal. Specially trained triage nurses categorised all patients at registration. This facilitated categorisation of attendances as "emergency" or "nonemergency". Comprehensive details of this triage system have been published previously. Disposal categories were: "hospital: outpatient department", "hospital: admit", "general practitioner", or "other". "Other" includes those 
Table 1 Frequency of AEE visits made by 34908 patients in 1995

\begin{tabular}{lcccc}
\hline $\begin{array}{l}\text { Frequency of } \\
\text { visits }\end{array}$ & No (\%) of patients & $\begin{array}{l}\text { Cumulative } \\
\text { \% of patients }\end{array}$ & No (\%) of visits & $\begin{array}{l}\text { Cumulative } \\
\% \text { of visits }\end{array}$ \\
\hline 1 & $27943(80.0)$ & 80.0 & $27943(59.8)$ & 59.8 \\
2 & $4758(13.6)$ & 93.7 & $9516(20.4)$ & 80.2 \\
3 & $1252(3.6)$ & 97.3 & $3756(8.0)$ & 88.2 \\
4 & $458(1.3)$ & 98.6 & $1832(3.9)$ & 92.1 \\
5 & $187(0.5)$ & 99.1 & $935(2.0)$ & 94.1 \\
6 & $105(0.3)$ & 99.4 & $630(1.3)$ & 95.5 \\
7 & $65(0.2)$ & 99.6 & $455(1.0)$ & 96.4 \\
8 & $39(0.1)$ & 99.7 & $312(0.7)$ & 97.1 \\
9 & $27(0.1)$ & 99.8 & $243(0.5)$ & 97.6 \\
10 & $20(0.1)$ & 99.8 & $200(0.4)$ & 98.0 \\
$11-15$ & $32(0.1)$ & 99.9 & $399(0.9)$ & 98.9 \\
$16-20$ & $12(0.0)$ & 100.0 & $210(0.4)$ & 99.3 \\
$>20$ & $10(0.0)$ & 100.0 & $304(0.7)$ & 100.0 \\
Totals & 34908 & & 46735 & \\
\hline
\end{tabular}

patients discharged but not referred to a general practitioner and those who did not wait to be seen. Each attendance was also categorised by the total number of attendances which the patient had made during the study period.

Everyone who attends the A\&E department at St James's is provided at registration with a unique identifying number that is used for that index visit and any subsequent visits to the A\&E department. This facilitated the production of a second dataset, comprising the individuals ("attenders") who made the $A \& E$ visits ("attendances") during 1995. For each attender the following information was recorded: age, sex, postal code of residence, socioeconomic status, marital status, and number of attendances during 1995. St James's Hospital is located in the Dublin 8 postcode area; all patient addresses were categorised as Dublin 8 or "other". Socioeconomic status was determined by general medical services (GMS) eligibility. Roughly one third of the population in the Republic of Ireland has access to free primary care and medications; they are described as GMS eligible. The other two thirds, whose income is above a certain level (for example in 1995, IR£ 82.50 per week for a single person aged up to 66 who is living alone), are responsible for their own primary health care costs. GMS eligible patients therefore represent the poorest sector of the community.

Both datasets were formed using Epi-Info software. Statistical analysis was performed using $\chi^{2}$ for linear trend and Kruskal-Wallis tests. As disposal was a multiple category dependent variable, multinominal logistic regression was performed for interpretation of these results. Not all records were complete; percentages given below refer to proportions of patients for whom data were retrieved.

\section{Results}

Table 1 illustrates the frequency of the 46735 attendances made by the $34908 \mathrm{~A} \& \mathrm{E}$ attenders in 1995. Altogether 205 patients (0.6\%) attended the department on seven or more occasions accounting for a total of 2123 visits (4.5\%); 955 patients $(2.7 \%)$ attended the department on more than three occasions accounting for a total of 5520 visits (11.8\%).

Characteristics of all attenders are shown in table 2. Age was not available for 459 attenders. The median age of all attenders was 35 (interquartile range 23-53). Increasing frequency of attendance was significantly associated with increasing age (Kruskal-Wallis $<0.001$ ), with being male ( $\chi^{2}$ for linear trend $14.06, \mathrm{p}<0.001)$, having a postal address in Dublin $8 \quad\left(\chi^{2}\right.$ for linear trend 279.79, $\mathrm{p}<0.0001)$, and with GMS eligibility $\left(\chi^{2}\right.$ for linear trend 781.67, $\mathrm{p}<0.0001)$. Being married was inversely associated with increasing frequency of attendance ( $\chi^{2}$ for linear trend 33.91, $\mathrm{p}<0.00001$ )

Each attendance was categorised according to the total number of attendances that the attender had made (table 3 ). The total number of attendances in these results is 46914 (an excess of 179). This excess is due to the inappropriate inclusion of records with missing triage codes on the mainframe computer. Increasing frequency of attendance was significantly associated with attendance between the hours of 1700 and 0900 ( $\chi^{2}$ for linear trend $295.62, \mathrm{p}<0.0001$ ), being triaged as a nonemergency $\left(\chi^{2}\right.$ for linear trend 1254.33, $\mathrm{p}<0.0001)$, and being self referred $\left(\chi^{2}\right.$ for linear trend $141.4, p<0.0001$ )

Attendances were distributed equally throughout the week with no association between the day and frequency of attendance (data available from authors). Multinominal regression showed that, relative to the risk of being discharged home, increasing frequency of attendance was associated with a decreased chance of being discharged to a general

Table 2 Age, sex, address, GMS eligibility, and marital status of $A \mathcal{E} E$ attenders according to the frequency of attendance

\begin{tabular}{llrrrr}
\hline Frequency of attendance & $\begin{array}{l}\text { Median age } \\
\text { (interquartile } \\
\text { range) }\end{array}$ & $\begin{array}{l}\text { No (\%*) of male } \\
\text { patients }\end{array}$ & $\begin{array}{l}\text { No (\%*) of } \\
\text { addresses in } \\
\text { Dublin } 8\end{array}$ & $\begin{array}{l}\text { No (\%*) of GMS } \\
\text { eligible patients }\end{array}$ & $\begin{array}{l}\text { No (\%*) of } \\
\text { married patients }\end{array}$ \\
\hline 1 & $34(23-52)$ & $15744(56.3)$ & $3317(11.9)$ & $11715(41.9)$ & $10702(38.3)$ \\
2 & $37(23-58)$ & $2746(57.7)$ & $801(16.8)$ & $2569(54.0)$ & $1784(37.5)$ \\
3 & $39(24-62)$ & $758(60.5)$ & $257(20.5)$ & $825(65.9)$ & $432(34.5)$ \\
4 & $43(26-67)$ & $258(56.3)$ & $108(23.6)$ & $320(69.9)$ & $138(30.1)$ \\
5 & $45(25-68)$ & $105(56.1)$ & $51(27.3)$ & $140(74.9)$ & $56(29.9)$ \\
6 & $47(35-66)$ & $59(56.2)$ & $28(26.7)$ & $91(86.7)$ & $33(31.4)$ \\
7 & $45(30-66)$ & $41(63.1)$ & $15(23.1)$ & $49(75.4)$ & $21(32.3)$ \\
8 & $39(30-60)$ & $28(71.8)$ & $14(35.9)$ & $35(89.7)$ & $9(23.1)$ \\
9 & $37(26-53)$ & $18(66.7)$ & $8(29.6)$ & $24(88.9)$ & $10(37.0)$ \\
10 & $52(38-67)$ & $13(65.0)$ & $5(25.0)$ & $16(80.0)$ & $8(40.0)$ \\
$11-15$ & $44(34-55)$ & $24(75.0)$ & $13(40.6)$ & $30(93.8)$ & $3(9.4)$ \\
$16-20$ & $40(29-50)$ & $7(58.3)$ & $5(41.7)$ & $12(100)$ & $2(16.7)$ \\
$>20$ & $46(39-58)$ & $8(80.0)$ & $3(30.0)$ & $10(100)$ & $3(30.0)$ \\
Subtotals & & $19809(56.7)$ & $4625(13.2)$ & $15836(45.4)$ & $13201(37.8)$ \\
Total for whom data was available & 34449 & 34908 & 34908 & 34908 & 34908 \\
\hline
\end{tabular}

${ }^{\star}$ As a percentage of patients who attended for that frequency. 
Table 3 Time, triage category, and referral source of $A \mathcal{E} E$ attendances according to the frequency of attendance

\begin{tabular}{lccr}
\hline Frequency of attendance & $\begin{array}{l}\left.\text { No } \%^{\star}\right) \text { of } \\
\text { attendances between } \\
1700 \text { and } 0900\end{array}$ & $\begin{array}{l}\text { No }\left(\%^{\star}\right) \text { of } \\
\text { attendances triaged } \\
\text { as non-emergency }\end{array}$ & $\begin{array}{l}\text { No (\%*) of } \\
\text { attendances } \\
\text { self-referred }\end{array}$ \\
\hline 1 & $13321(47.5)$ & $23998(85.6)$ & $22356(79.7)$ \\
2 & $4584(48.0)$ & $8061(84.4)$ & $7681(80.5)$ \\
3 & $1884(49.8)$ & $3034(80.2)$ & $3077(81.4)$ \\
4 & $938(51.0)$ & $1466(79.6)$ & $1484(80.6)$ \\
5 & $491(52.2)$ & $735(78.2)$ & $772(82.1)$ \\
6 & $359(56.8)$ & $470(74.4)$ & $529(83.7)$ \\
7 & $291(63.8)$ & $331(72.6)$ & $408(89.5)$ \\
8 & $192(61.3)$ & $253(80.8)$ & $288(92.0)$ \\
9 & $147(59.5)$ & $192(77.7)$ & $211(85.4)$ \\
10 & $115(57.2)$ & $154(76.6)$ & $181(90.0)$ \\
$11-15$ & $272(67.8)$ & $322(80.3)$ & $366(91.3)$ \\
$16-20$ & $145(68.4)$ & $195(92.0)$ & $195(92.0)$ \\
$>20$ & $243(79.4)$ & $280(92.5)$ & $284(92.8)$ \\
Subtotals & $22982(49.0)$ & $39491(84.2)$ & $37832(80.6)$ \\
Total for whom data was available & 46914 & 46914 & 46914 \\
\hline
\end{tabular}

^As a percentage of attendances by patients who attended for that frequency.

Table 4 Results of other international studies reviewing characteristics of attendances to $A \mathcal{E} E$ departments

\begin{tabular}{lllll}
\hline & $\begin{array}{l}\text { Year of } \\
\text { study }\end{array}$ & $\begin{array}{l}\text { Definition of "frequent } \\
\text { attender" (visits in } \\
\text { previous year) }\end{array}$ & $\begin{array}{l}\text { \% Defined as } \\
\text { frequent }\end{array}$ & $\begin{array}{l}\text { \% Of visits } \\
\text { performed by } \\
\text { frequent attenders }\end{array}$ \\
\hline Stockholm $^{2}$ & 1980 & $>3$ & NA & NA \\
Stockholm $^{3}$ & 1977 & $>3$ & 11 & 32 \\
Connecticut $^{4}$ & 1980 & $>2$ & 23 & 73 \\
Portland $^{5}$ & 1987 & $>3$ & 8 & 24 \\
Ontario" $^{7}$ & 1990 & $>1$ & 30 & 59
\end{tabular}

NA $=$ not available.

practitioner (relative risk of $0.98 ; 95 \%$ confidence interval (CI) 0.97 to 0.99 ) and an increased risk of being referred to the outpatient department (relative risk of $1.12 ; 95 \%$ CI 1.11 to 1.13 ).

\section{Discussion}

The results of this study need to be interpreted cautiously, as the data were collected retrospectively from one source in a single hospital. Data capture was not complete (tables 2 and 3) but was acceptable. The study suggests that a small number of patients does account for a disproportionately large percentage of the total number of departmental attendances.

Increasing frequency of attendance was associated with increasing age, being male, being poor, living close to the hospital, and not being married (table 2). Attendances of such attenders were more likely to be self referred non-emergencies between the hours of 1700 and 0900 (table 3). Some or all of these findings are consistent with studies from Ontario, ${ }^{7}$ Stockholm, ${ }^{2}$ Paris, ${ }^{8}$ Oregon, ${ }^{5}$ and New Haven. ${ }^{4}$ All of these studies used an arbitrary definition of frequent use (usually more than three visits in the previous year). Triangulation with the results of this study, which utilised a different methodology, is therefore noteworthy. Table 4 presents the results of these international studies. Using a definition of more than three visits, the figures reported in this study, of $2.7 \%$ of patients accounting for $11.8 \%$ of visits, are relatively low.

No follow up of frequent attenders was attempted in this study. Andren and Rosenqvist in Stockholm followed up 232 people who had made four or more $A \& E$ attendances in the previous year. ${ }^{9}$ The standardised mortality ratio during the first follow up year was $590 \%$ for males and $740 \%$ for females. Hansagi and coworkers, also reporting from Stockholm, confirmed these findings and suggested that the most important excess mortality was from violent death. ${ }^{10}$ These mortality figures, taken in conjunction with the social profile suggested by this and other papers, suggest that frequent attenders are a highly vulnerable group. Such patients are definitively different from the usual profile of frequent general practice attenders who are usually young females. ${ }^{11}$ It may be that frequent $A \& E$ attenders represent a vulnerable group of patients whose needs remain unmet despite multiple encounters with many different care providers.

Conflict of interest: none.

Funding: none.

1 Malone RE. Heavy users of emergency services: social construction of a policy problem. Soc Sci Med 1995;40:469-77.

2 Andren KG, Rosenqvist U. Heavy users of an emergency department: psycho-social and medical characteristics, other health care contacts and the effect of a hospital social worker intervention. Soc Sci Med 1985;21:761-70.

3 Hansagi H, Edhag O, Allebeck P. High consumers of healthcare in emergency units: how to improve their quality of care. Quality Assurance in Health Care 1991;3:51-62.

4 Schneider KC, Dove HG. High users of VA emergency room facilities: are outpatients abusing the system or is the system abusing them? Inquiry 1983;20:57-64.

5 Hansen TE, Elliott KD. Frequent psychiatric visitors to a veterans affairs medical centre emergency care unit. Hospital $\mathcal{E}^{\circ}$ Community Psychiatry 1993;44:372-5.

6 Murphy AW, Bury G, Plunkett PK, et al. A comparison of Murphy AW, Bury G, Plunkett PK, et al. A comparison of general practitioner and usual medical care in an urban
A\&E department in terms of process, health status and A\&E department in terms of process, heal
comparative costs. BMF 1996;312:1135-42.

7 Brown EM, Goel V. Factors related to emergency department use: results from the Ontario Health Survey 1990. Ann Emerg Med 1994;24:1083-91.

8 Lang T, Davido A, Diakite B, et al. Using the hospital emergency department as a regular source of care. Eur $\mathcal{f}$ Epidemiol 1987;13:223-8.

9 Andren KG, Rosenqvist U. Heavy users of an emergency department-a two year follow up-study. Soc $S c i$ Med $1987 ; 25: 825-31$.

10 Hansagi $\mathrm{H}$, Allebeck $\mathrm{P}$, Edhag $\mathrm{O}$, et al. Frequency of emergency department attendances as a predictor of mortality: nine year follow-up of a population based cohort. $\mathcal{f}$ Public nine year follow-up of a popul

11 Schrire S. Frequent attenders-a review. Fam Pract 1986;11:424-30. 